\title{
Delayed release pancrelipase for the treatment of pancreatic exocrine insufficiency associated with cystic fibrosis
}

\author{
Susan S Baker \\ Department of Pediatrics, University \\ at Buffalo, Buffalo, NY, USA
}

\begin{abstract}
Pancreatic enzyme replacement therapy (PERT) is the only treatment for malabsorption in cystic fibrosis (CF) caused by pancreatic insufficiency (PI). PI occurs in approximately $85 \%$ of patients with CF. PERT overcomes some, but not all the signs and symptoms of malabsorption. Clinical parameters such as growth, abdominal pain, diarrhea and gassiness, commonly used to adjust PERT dosing, are shown not to be good indicators of their effectiveness. The FDA does not provide oversight of preparations of pancreatic enzymes consistent with the oversight it provides for all other drugs. The FDA intends to rectify this situation. Measures of the effectiveness of PERT are limited to the coefficient of fat absorption, a difficult and unpleasant exercise for patients.
\end{abstract}

Keywords: pancrelipase, cystic fibrosis, malabsorption, pancreatic enzymes

\section{Introduction}

Malnutrition is a common finding in people who have cystic fibrosis (CF) and malnutrition correlates with poor outcomes. Malnutrition occurs because of inadequate intake, increased losses, malabsorption of nutrients, or increased requirements. All of these occur in people who have $\mathrm{CF}$; however, the most prominent cause of malnutrition is malabsorption. There are many possible causes for malabsorption, including dysfunction of small bowel or liver and bacterial overgrowth, nevertheless, exocrine pancreatic insufficiency is the most important cause in CF. Provision of pancreatic enzymes improves malabsorption, but does not return the absorptive function of the gastrointestinal tract to normal. Although there are many possible explanations, the focus of this article is on pancreatic enzyme replacements in cystic fibrosis.

\section{Pancreatic enzyme development}

Currently, all available pancreatic enzyme replacements for therapy (PERT) are porcine in origin. The first formulations were powders obtained by freeze drying hog pancrease and administered as the crude product or after some extraction and purification. They improved fat absorption, but much of the enzyme was inactivated in the acid-pepsin containing milieu of the stomach. To prevent inactivation of enzymes by acid, bicarbonate was administered with the enzyme or medication that suppressed acid was prescribed. Whether decreasing acid improved the efficacy of the preparations is not clear (Ng and Jones 2008). Enteric coated enzymes were next developed. The coating protected the enzymes so they were resistant to acid. This allowed delivery of the intact enzyme to the duodenum and improved efficacy, but did not completely prevent malabsorption. There are several possible reasons, products may deteriorate while on the shelf, activity of the crude extracts may vary, other proteins or substances in the 
products may inactivate the enzymes, the coated enzymes may not leave the stomach at the same time as gastric fat, the acid resistant coating may not dissolve, enzymes may not be released in the proximal intestine or patient specific factors such as gastric acidity, motility or interaction with other medications may exist. New nonporcine enzyme products are in clinical trials (Borowitz et al 2006). These products in which the lipase, protease, and amylase are produced and purified independently take advantage of crystallization and cross-linking of proteins.

Pancrealipase is a substance containing principally lipase, amylase and protease obtained from the pancreas of the hog. Each mg contains not less than 24 USP units of lipase, not less than 100 USP units of amylase and not less than 100 USP units of protease. Units of lipase activity are based on the rate of hydrolysis of olive oil, those of protease activity on the rate of hydrolysis of casein and those of amylase activity on the rate of hydrolysis of starch. (Sweetman 2007).

Pancrelipase cannot be sold without a prescription. Generic products exist. However, generic products may not be as efficacious as the named brands (Hendeles et al 1990).

In fact, there is a plethora of porcine based enzyme replacements from powders to minimicrospheres with alkalinizing components. An updated list of pancrelipase formulations is available (Medline Plus 2008). Specific information on these products is not available because it is guarded as proprietary. There are many studies that attempt to demonstrate and/or compare the efficacy of different preparations. However, it is difficult at best to interpret the whole of these studies with any logic because of uncertainty in the product contents and activities. Making this difficult situation even worse is the fact that measures of treatment outcomes, including the gold standard, 72 hour coefficient of fat absorption (CFA) (Borowitz et al 2005), are not reliable.

\section{FDA oversight}

In a 2004 (Department of Health and Human Services 2004) review of enzyme products, the FDA found inconsistencies in the formulation, composition, enzymatic activities, dosage, stability, bioavailability, and manufacturing processes of enzymes that could significantly compromise the safety and effectiveness of the drugs. None of the enzyme products on the market have received FDA approval because the development and marketing of pancreatic enzymes predate the 1938 passage of the FDA approval act. The FDA allowed these products to be grandfathered and to remain on the market because of their lifesaving benefits. However, the lack of quality and consistency is of such concern that the FDA required that all enzyme products achieve FDA approval by 2008. In October, 2007 the FDA issued an extension to 2010 if the manufacturers have investigational new drug applications on active status on or before April 28, 2008 and have submitted new drug applications on or before April 28, 2009. This extension was granted to ensure the availability of exocrine pancreatic drug products during the additional time needed to obtain marketing approval (Department of Health and Human Services 2007). As noted by the FDA, there is no oversight for pancrealipase as there is for other drugs and there is variability among the preparations. It is questionable if the FDA will be successful in gaining the control it desires over the current products on the market because there is no incentive for manufacturers of these enzymes to meet FDA requirements. There is no likelihood that the FDA would withdraw all pancreatic enzymes from the market because of the hardship and negative impact on the health of those with CF this would create. Representatives of the manufacturers, however, are clear that they want to meet the FDA requirements, but doing so will require considerable time and resources.

\section{Indications for PERT}

The most common reason for prescribing PERT is cystic fibrosis where approximately $85 \%$ of the patients are pancreatic insufficient (PI) (Borowitz et al 2004). PERT is also prescribed for people who have Shwachman-Diamond Syndrome and PI that develops after an initially normal functioning pancreas is no longer capable of secretion, such as occurs after chronic pancreatitis from a variety of causes. Pancreatic enzymes are prescribed for pain control in chronic pancreatitis, but this use is controversial (Layer et al 2001).

\section{Cystic fibrosis}

Cystic fibrosis (CF) is an autosomal recessive disease affecting epithelial secretory tissues and manifested as pulmonary and pancreatic dysfunction. The incidence of CF is 1:3200 (Turcios 2005 ) live births among Caucasians. CF is caused by mutations in the gene that encodes the cystic fibrosis transmembrane conductance regulator (CFTR) protein. CFTR is an epithelial cell chloride channel that is highly conserved among species and has a wide tissue distribution. It is expressed in many tissues including respiratory tract epithelia, sweat glands, pancreatic ducts, liver, colon, parotid gland, kidney, and seminiferous tubules. CFTR functions as a chloride channel and controls the regulation of other transport pathways. Mutations in the CFTR gene 
cause cystic fibrosis and congenital bilateral aplasia of the vas deferens (OMIM 2008). Failure of the CFTR protein to function results in impaired chloride transport at the apical surface of epithelial cells and dysregulation of other transporters such as chloride-coupled bicarbonate transport (Choi et al 2001) and sodium channel activity (Reddy et al 1999). Normal tissues secrete alkaline fluids but mutant CFTR expressing tissues secrete acidic fluids. Bicarbonate and $\mathrm{pH}$ affect mucin viscosity and bacterial binding. The result is low volume, high salt fluid in the extracellular space. Although inspissation of zymogen may be the earliest pancreatic lesion in CF, mucous metaplasia follows (Tucker et al 2003). The viscous secretions cause luminal obstruction of ducts and that leads to acinar cell destruction, fibrosis and exocrine PI. The resulting PI is characterized by the decrease or absence of the exocrine pancreatic enzymes, amylase, proteases, lipase, colipase and phospholipases while salivary and brush border amylases are normal or elevated and lingual lipase levels are elevated (Guy-Crotte et al 1996). Pancreatic dysfunction is thought to be the main cause of severe malabsorption and poor nutrition in $\mathrm{CF}$.

\section{Pancreatic function in CF}

Protein digestion begins in the stomach by acid hydrolysis and continues by brush border proteolytic enzymes. Similarly starch digestion can be achieved by salivary amylase and brush border oligosaccharidases. Protein and starch digestion are maintained even when virtually all pancreatic function is blocked. Fat malabsorption is the most important digestive malfunction in pancreatic exocrine insufficiency and is associated with abdominal pain, steatorrhea, flatulence, diarrhea, and deficits in energy and the fat soluble vitamins A, D, E, and K. Malabsorption causes growth failure and specific nutrient deficiencies in children.

Nutrient delivery into the proximal small bowel is the most important stimulus of exocrine pancreatic secretion. Free fatty acids cause release of cholecystokinin and this stimulates pancreatic secretion (Guimbaud et al 1997). The pancreas has a high reserve capacity. Clinically significant malabsorption is usually not detectable until 90\%-95\% of the secreting parenchyma is destroyed (DiMagno et al 1973). When pancreatic enzyme output decreases by $60 \%-90 \%$ it is likely that the site of maximal digestion and absorption shifts from the duodenum to more distal small bowel. Increased amounts of nutrients are delivered to the distal ileum and this causes disturbances in motor and secretory function of the upper gastrointestinal organs (Keller et al 1988; Layer et al 1997).

\section{Enzyme dosing}

Dosing of pancreatic enzymes is an inexact science. Treatment of malabsorption requires delivery of sufficient enzyme activity into the duodenal lumen simultaneously with a meal. To achieve this, $40-60 \mathrm{U} / \mathrm{mL}$ of lipase activity are required. This is about 25,000 to 40,000 units/meal (Layer et al 1992) for adults.

For children, estimates for dosing of enzymes are based on lipase as well beginning with 1,000 lipase units $/ \mathrm{kg}$ per meal for children less than 4 years of age and at 500 lipase units/kg per meal for those older than 4 years of age (Borowitz 1995). Fewer enzymes per kilogram of body weight are recommended in older children because they tend to eat less fat per kilogram of body weight. For snacks half the dose is recommended since the food intake is less.

Infants may be given 2,000 to 4,000 units per $120 \mathrm{~mL}$ of infant formula or per breast feeding. The infant's mouth should be swept after administration to prevent ulceration in the alkaline salivary environment (Borowitz et al 1995).

The daily dose for most patients is less than 10,000 units of lipase $/ \mathrm{kg}$ per day or 6,000 units of lipase $/ \mathrm{kg}$ per meal (Borowitz et al 1995; FitzSimmons et al 1999) to prevent fibrosing colonopathy.

For patients who cannot swallow capsules, delayed release capsules containing enteric coated microspheres or microtablets may be opened and the contents sprinkled on soft food that does not require chewing and has a low $\mathrm{pH}$ such as applesauce, gelatins, or pureed apricot, banana or sweet potatoes. Foods having a $\mathrm{pH}$ greater than 7.3, such as milk, custard or ice cream should be avoided as a vehicle for the sprinkled enzymes because the protective enteric coating can dissolve.

Pancrealipase tablets or capsules should not be crushed or chewed. If powder spills on skin, it should wash it off immediately. Care should be taken not to inhale the powder as it can be irritating to the respiratory tract.

\section{Assessment of pancreatic function}

The test that most accurately estimates pancreatic function is the secretin-pancreozymin stimulation test. This test requires duodenal intubation and collection of fluid before and after intravenous hormonal stimulation of the pancreas (Cooper 1996). It is invasive, expensive and time consuming and although it defines PI it cannot be used to monitor the effectiveness of PERT. Similarly, serum immunoreactive trypsinogen, stool chymotrypsin or stool elastase assess pancreatic function, but cannot be used to monitor the effectiveness of PERT. 
The most commonly performed test of pancreatic function is the 72-hour CFA. It does not discriminate among hepatobiliary, mucosal or pancreatic causes for fat malabsorption. Intake must be carefully recorded, and many people find the stool collection onerous. But, it is the only clinical available test that can be used to assess PERT (Borowitz et al 2006).

\section{Clinical outcomes}

Patients with PI take PERT to compensate for exocrine PI and improve nutrient absorption. PERT dosing is adjusted based on growth for children and on whether signs and symptoms of malabsorption are present or persist (Borowitz et al 1995, 2002) on a given dose of enzymes. Signs and symptoms of malabsorption are usually self-reported and include frequent or loose bowel movements, excessive gas and stomach aches. Following is a discussion of growth, patient reported symptoms of malabsorption and PERT dosing in a cohort of 1,215 patients with CF (Borowitz et al 2004; Baker et al 2005).

Growth is a necessary, but not sufficient indicator of overall health in children. Patients with CF should have normal growth (Borowitz 2002) and poor clinical outcomes are associated with undernutrition in patients with CF (Kraemer et al 1978; Corey et al 1988; Dazell et al 1992; Kerem et al 1992; Pencharz and Durie 1993; Beker et al 2001). Malabsorption secondary to PI is the most common reason for malnutrition in $\mathrm{CF}$.

In a multicenter study of 1,215 patients with CF (Baker et al 2005) $93.4 \%$ of subjects were prescribed PERT and 91.4\% reported taking the enzymes. The reported adherence to PERT is remarkable since typical adherence rates are about $50 \%$ for medications and lower for behaviorally demanding regimens (Haynes et al 2002). This study did not attempt to confirm the reported adherence by more specific measures such as pill counting because simply asking patients about their adherence detects more than $50 \%$ of those with low adherence with a specificity of $87 \%$ (Stephenson et al 1993).

Differences in growth among different age groups were identified, but as a whole PI patients had better growth, and when growth was completed, healthier BMI than PS patients because of the higher frequency of obesity in PS patients. For patients $>20$ years of age $49.2 \%$ of the PS and $14.5 \%$ of the PI patients had a BMI $\geq 24.9$. For patients 3 to 20 years of age, $28.6 \%$ of the PS and $18.1 \%$ of the PI patients had a BMI $\geq$ the 75 th percentile for age. For patients less than 3 years of age, $24.1 \%$ of the PS and $14.2 \%$ of the PI patients had a weight-height ratio $\geq$ the $75 \%$ for age. The UK data base of CF shows that $10.2 \%$ of all patients with $\mathrm{CF}$ are overweight or obese (Kastner-Cole et al 2005). Of note, varying the dose of PERT from less than 500 units $/ \mathrm{kg} / \mathrm{meal}$ to 2,500 and more units $/ \mathrm{kg} /$ meal did not correlate with growth.

\section{Clinical symptoms}

Abdominal pain occurred at least once a week in $9.6 \%$ of patients (PS or PI) with CF, approximately the same incidence as the general population (Apley and Naish 1958; Hyams et al 1966; Rasquin-Weber et al 2000). No relationship was found between abdominal pain and PERT intake from $<500$ to $>2,500$ lipase units $/ \mathrm{kg} /$ meal, suggesting that pancreatic exocrine insufficiency was not the main cause of abdominal pain and that increasing the dose of PERT would not alleviate these symptoms.

In the general population the incidence of constipation varies from about 15\% in adults (Stewart 1999) to 34\%-37\% in children from birth to 12 years (Loening-Baucke 1998). In a chart review of 168 patients with CF ranging in age from less than 5 years to over 30 years, Rubinstein et al (1986) noted an incidence of constipation of $32 \%$. Rubinstein et al did not differentiate between PI and PS patients. We observed a higher incidence of constipation in the PI patients, about 1.5 times that of the PS patients. We did not observe an increase in constipation with increasing age (Baker et al 2005). Further, there was no correlation between constipation and the PERT dose suggesting that constipation cannot be used as a marker for inappropriate PERT dosing. The commonly held belief that constipation is a consequence of high enzyme doses is not supported by these data.

About 1.6 times more patients with PI reported gassiness compared to PS. Our results showed that increasing PERT dose does not improve the patients' subjective sense of gassiness. The prevalence of gassiness was strikingly similar to that of constipation and raised the suggestion that treatment for constipation be offered for gassy patients.

There was no significant difference between PS and PI patients in the number of stools/day. In general, both PI and PS patients reported more stools per day than the non-CF population. Since diarrhea is the main clinical expression of malabsorption (Schmitz 2000) we expected to find more patients with PI reporting a higher number of stools per day compared to PS. We also expected that in the PI patients increasing the PERT dose would be associated with fewer stools. In fact we found no difference between the PI and PS patients in the reported frequency of stools and PERT dosing had no effect on the reported number of stools. This suggests the number of stools per day is not a good clinical discriminator for making decisions about PERT dosing. 
There are several reasons that outcome measures such as growth and symptoms such as abdominal pain, constipation, flatulence and diarrhea may respond differently to PERT than anticipated. The patients may choose not to adhere to the prescribed medication, the enzymes may not be as effective as expected, or factors other than pancreatic exocrine insufficiency may be causing the symptoms or contributing to them.

\section{Conclusion}

The treatment and monitoring of malnutrition in people with $\mathrm{CF}$ is a difficult and inexact science. PI occurs in approximately $15 \%$ of patients with CF. PERT overcomes some, but not all the signs and symptoms of malabsorption and clinical parameters commonly used to adjust PERT dosing are shown not to be good discriminators. The FDA does not provide oversight of preparations of pancreatic enzymes consistent with the oversight it provides for all other drugs. The FDA is attempting to rectify this situation. Measures of the effectiveness of PERT are limited to CFA, a difficult and unpleasant exercise for patients.

\section{Abbreviations}

$\mathrm{CF}$, cystic fibrosis; CFA, coefficient of fat absorption; CFTR, cystic fibrosis transmenbrane conductance regulator; FDA, US Food and Drug Administration; PERT, pancreatic enzyme replacement therapy; PI, pancreatic insufficient; PS, pancreatic sufficient; UPS.

\section{Disclosures}

The author has no conflicts of interest to disclose.

\section{References}

Apley J, Naish N. 1958. Recurrent abdominal pain: a field survey of 1,000 school children. Arch Dis Child, 33:165-70.

Baker SS, Borowitz D, Duffy L, et al. 2005. Pancreatic enzyme therapy and clinical outcomes in patients with cystic fibrosis. J Pediatr, 146:189-93.

Beker LT, Russek-Cohen E, Fink RJ. 2001. Stature as a prognostic factor in cystic fibrosis survival. $J$ Am Diet Assoc, 101:438-42.

Borowitz DS, Grand RJ, Durie PR. 1995. Consensus Committee. Use of pancreatic enzyme supplements for patients with cystic fibrosis in the context of fibrosing colonopathy. J Pediatr, 127:681-4.

Borowitz D, Baker RD, Stallings V. 2002. Consensus report on nutrition for pediatric patients with cystic fibrosis. J Pediatr Gastroenterol Nutr, 35:246-59.

Borowitz D, Baker SS, Duffy L, et al. 2004. Use of fecal elastase-1 to classify pancreatic status in patients with cystic fibrosis. $J$ Pediatr, 145:322-6.

Borowitz D, Durie PR, Clarke LL. 2005. Gastrointestinal Outcomes and Confounders in Cystic Fibrosis. . J Pediatr Gastroenterol Nutr, 41:273-85.

Borowitz D, Goss CH, Simauro S, et al. 2006. Study of a novel pancreatic enzyme replacement therapy in pancreatic insufficient subjects with cystic fibrosis. $J$ Pediatr, 149:658-62.
Choi JY, Muallem D, Kiselyov K, et al. 2001. Aberrant CFTR-dependent $\mathrm{HCO}(-3)$ transport in mutations associated with cystic fibrosis. Nature, 410:94-97.

Cooper R. 1996. Pancreatic function tests. In: Walker, et al. (eds) Pediatric Gastrointestinal Disease. 2nd ed. St. Louis: Mosby. p. 1621-34.

Corey M, McLaughlin FJ, Williams M, et al. 1988. A comparison of survival, growth and pulmonary function in patients with cystic fibrosis in Boston and Toronto. J Clin Epidemiol, 41:588-91.

Dalzell AM, Shepherd RW, Dean SB, et al. 1992. Nutritional rehabilitation in cystic fibrosis: a 5 year follow-up study. $J$ Pediatr Gastroenterol Nutr, 15:141-45.

Department of Health and Human Services. Federal Register. 2004. Exocrine Pancreatic Insufficiency Drug Products 69:23410.

Department of Health and Human Services. Federal Register. 2007. Exocrine Pancreatic Insufficiency Drug Products; Extension to Obtain Marketing Approval. 72:60860-62.

DiMagno EP, Go VLW, Summerskill WHJ. 1973. Relations between pancreatic enzyme outputs and malabsorption in severe pancreatic insufficiency. N Engl J Med, 288:813-15.

FitzSimmons SC, Burkhart GA, Borowitz D, et al. 1998. High-dose pancreatic-enzyme supplements and fibrosing colonopathy in children with cystic fibrosis. $N$ Engl J Med, 336:1283-1289.

Guy-Crotte O, Carrere J, Figarella C 1996. Exocrine pancreatic function in cystic fibrosis. Eur J Gastroenterol Hepatol, 8:755-9.

Guimbaud R, Moreau JA, Bouisson M, et al. 1997. Intraduodenal free fatty acids rather than triglycerides are responsible for the release of CCK in humans. Pancreas, 14:76-82.

Haynes RB, McDonald HP, Garg AX . 2002. Helping patients follow prescribed treatment: Clinical applications. JAMA, 288:2880-3.

Hendeles L, Dorf A, Stecenko A, et al. 1990. Treatment failure after substitution of generic pancrelipase capsules. JAMA, 263:2459-61.

Hyams JS, Burke G, Davis PM, et al. 1996. Abdominal pain and irritable bowel syndrome in adolescents: a community-based study. J Pediatr, 129:220-6.

John Hopkins University On Line Mendelian Inheritance in Man (OMIM). Accessed 2 April 2008. URL: http://www.ncbi.nlm.nih.gov/entrez/ dispomim.cgi?id $=602421$.

Kastner-Cole D, Polin CAN, Ogston SA, et al. 2005. Overweight and obesity in [delta]F508 homozygous cystic fibrosis. J Pediatr, 147:402-4.

Keller J, Runzi M, Goebell H, et al. 1988. Duodenal and ileal nutrient deliveries regulate human intestinal motor and pancreatic responses to a meal. Am J Physio, 272:G632-7.

Kraemer R, Rudeberg A, Hadom B, et al. 1978. Relative underweight in cystic fibrosis and its prognostic value. Acta Paediatr Scand, 67:33-7.

Kerem E, Reisman J, Corey M, et al. 1992. Prediction of mortality in patients with cystic fibrosis. N Engl J Med, 326:1187-91.

Layer P, von der Ohe M, Gröger G, et al. 1992. Luminal availability and digestive efficacy of substituted enzymes in pancreatic insufficiency. Pancreas, 7:745.

Layer P, von der Ohe MR, Holst JJ, et al. 1997. Altered postprandial motility in chronic pancreatitis: role of malabsorption. Gastroenterology, 112:1624-34.

Layer P, Keller J, Lankish PG. 2001. Pancreatic enzyme replacement therapy. Curr Gastroenterol Rep, 3:101-8.

Loening-Baucke V. 1998. Constipation in children. $N$ Eng J Med, 339:1155-6.

Medline Plus. Accessed 2 April 2008. URL: http://www.nlm.nih.gov/ medlineplus/druginfo/medmaster/a604035.html

Ng SM, Jones AP. 2008. Drug therapies for reducing gastric acidity in people with cystic Fibrosis. The Cochrane Database of Systematic Reviews Accessed 2 April, 2008.

Pencharz PB, Durie PR. 1993. Nutritional management of cystic fibrosis. Ann Rev Nutr, 13:111-36.

Rasquin-Weber A, Hyman PE, Cucchiara S, et al. 1999. Childhood functional gastrointestinal disorders. Gut, 45(Suppl II):II60-8. 
Reddy MM, Light MJ, Quinton PM. 1999. Activation of the epithelial $\mathrm{Na}(+)$ channel $(\mathrm{ENaC})$ requires $\mathrm{CFTR} \mathrm{CI}(-)$ channel function. Nature, 402:301-4.

Rubinstein S, Moss R, Lewiston N. 1986. Constipation and meconium ileus equivalent in patients with cystic fibrosis. Pediatrics, 78:473-9.

Schmitz J. 2000. Maldigestion and malabsorption. In: Walker WA, Durie PR, Hamilton JR, et al. (eds). Pediatric gastrointestinal disease: pathophysiology, diagnosis, management. 2nd ed. St. Louis: Mosby. p. 51-8.

Stephenson BJ, Rowe BH, Haynes RB, et al. 1993. Is this patient taking the treatment as prescribed? JAMA, 269:2779-81.
Sweetman S. 2007. Martindale: The Complete Drug Reference Grayslake IL: Pharmaceutical Press.

Stewart WF, Liberman JN, Sandler RS, et al. 1999. Epidemiology of constipation (EPOC) study in the United States: relation of clinical subtypes to sociodemographic features. Am J Gastroenterol, 94:3530-40.

Turcios, NL. 2005. Cystic fibrosis, an overview. J Clin Gastroenterol, $34: 307-17$.

Tucker JA, Spock A, Spicer SS, et al. 2003. Inspissation of pancreatic zymogen material in cystic fibrosis. Ultrastruc Pathol, $27: 323-35$ 